\title{
Emergency Roadside Technician Dies When Struck by a Single-Unit Truck on an Interstate Shoulder
}

\section{Incident Number: 05KY001}

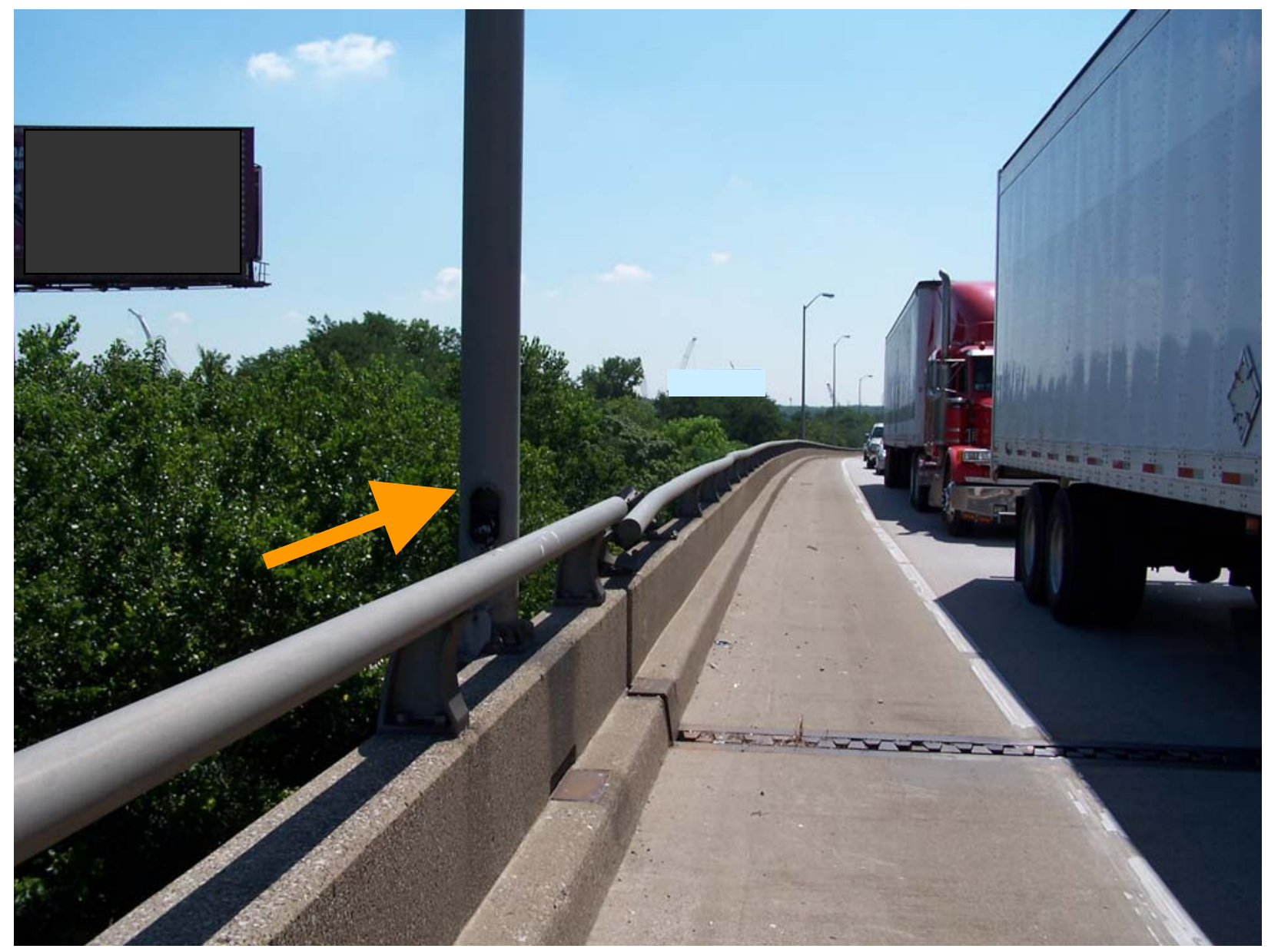

Location on bridge where responder attempted to avoid semi.

Kentucky Fatality Assessment and Control Evaluation Progran Kentucky Injury Prevention and Research Center 333 Waller Avenue

Suite 202

Lexington, Kentucky 40504

Phone: 859-323-2981

Fax: 859-257-3909

www.kiprc.uky.edu

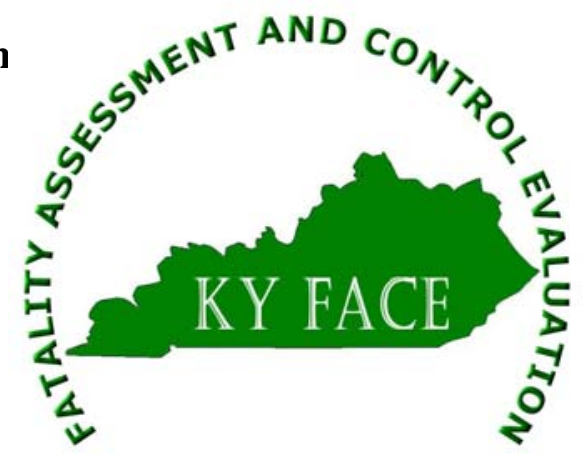


Kentucky Fatality Assessment and Control Evaluation (FACE) Program

Incident Number: 05KY001

Release Date:

August 3, 2007

Subject:

Emergency Roadside Technician Dies When Struck by
a Single-Unit Truck on an Interstate Shoulder

\section{Summary}

In the winter of 2005 a 52-year-old male emergency roadside technician (ERT), (providing traffic control support for police), died when he fell approximately 75 - 80 feet from a bridge after being struck by a single-unit truck. A policeman had responded to a call from a semi-truck driver on the interstate who had blown a tire while driving on an interstate. After the tire blew, the driver immediately pulled the semi onto the right shoulder and called police for assistance. This section of the shoulder was on a bridge on the blind side of a hill, and was too narrow to accommodate the width of the semi. The back left corner of the semi extended out into the righthand travel lane of the interstate. A police officer arrived and with emergency lights flashing, parked his cruiser on the shoulder at the top of the hill behind the semi. The officer requested assistance with traffic control. An employee of a company contracted by the local police to provide roadside assistance arrived in a panel truck. Upon arrival, he was instructed by the police officer to park his vehicle with yellow emergency lights flashing at the bottom of the hill, approximately 100 yards behind the police cruiser. After parking his vehicle on the shoulder as instructed, the contractor then exited the vehicle from the driver's side and proceeded to walk up the hill toward the police cruiser. A single-unit truck approached from behind in the right hand travel lane and tried to switch lanes when he observed the yellow emergency lights on the panel truck. When the driver of the single-unit truck switched to the middle lane, the driver struck the right-rear end of a semi trailer in the middle lane, lost control, swerved back into the right lane, sideswiped the ERT's panel truck, then struck the ERT. Upon being struck, the ERT was thrown over the side of the bridge $75-80$ feet to the ground below. The police officer called emergency medical services to the scene. They arrived and detected no vital signs in the ERT. The coroner was called and upon arrival, declared the ERT dead at the scene of "multiple blunt force injuries secondary to motor vehicle versus pedestrian”.

To prevent future occurrences of similar incidents, the following recommendations have been made:

Recommendation No. 1: A traffic control plan should be implemented and enforced immediately when the travel lane is obstructed.

Recommendation No. 2: Ensure that the placement of various types of warning devices (portable signs, orange traffic cones, flares and/or portable changeable message signs) informs drivers of what to expect when approaching an incident scene.

Recommendation No. 3: In addition to flashing lights, a permanent message board should be placed on the back of emergency response vehicles that routinely need to control traffic. 
Recommendation No. 4: Ensure that personnel receive training in the proper procedures and the hazards associated with emergency operations for highway incidents.

Recommendation No. 5: When providing emergency roadside assistance, company policy for exiting emergency vehicles away from the traffic lanes should be enforced.

\section{Recommendation No. 6: Braking mechanism performance checks should be routinely performed on all motor vehicles before entering roadways.}

\section{Background}

The decedent had been employed approximately six months by a company that provided roadside assistance to motorists and the local police department. The company employed 260 persons, 30 were emergency road service technicians who operated panel trucks and tow trucks (flat beds and hooks) to assist disabled motorists and the local police.

Prospective employees were required to undergo a background check, drug, and alcohol tests. Random drug and alcohol tests were performed on all employees after being hired. Emergency responder trainees had a 90 day trial period during which they rode with an experienced responder and were observed. Responsibilities included, but were not limited to, assisting motorists with disabled vehicles, and assisting police in placing triangles, flares or other warning devices to slow traffic during emergency situations. The company contract with the police department stated that when providing support for a roadside emergency, the ERT was to always park his/her vehicle behind the police officer's. One safety technique responders were taught was to exit their vehicles on the passenger side when responding to an incident on a busy roadway and to use common sense. Responders were equipped with ANSI-certified high visibility reflective vests and company uniforms.

\section{Investigation}

The Kentucky Fatality Assessment and Control Evaluation Program was notified via a newspaper report of an occupational fatality involving an ERT walking on the shoulder of a bridge on a busy interstate highway. The employer and the police at the scene of the incident were interviewed. The coroner record was also reviewed for this report.

At approximately 9:00 AM on a winter day in 2005, a semi blew a tire while driving westward on a six lane interstate highway. The speed limit was 55 miles per hour, the pavement was dry and the sky overcast. Realizing he had blown the tire, the driver immediately steered the semi onto the right shoulder and at 9:05 AM called police for assistance. The shoulder was on a bridge on the blind side of a hill, and was too narrow to accommodate the width of the semi. This caused the back left corner of the semi to extend into the right-hand travel lane of the interstate. A police officer arrived at the scene at 9:07 AM with emergency lights flashing, parked his cruiser on the bridge shoulder at the top of the hill approximately 50 yards behind the semi. The officer assessed the situation and called the company contracted to support police during roadway emergencies for assistance with traffic control. An ERT was radioed to report to the scene, however, he was engaged in assisting another disabled motorist in a separate incident. 
Another ERT heard the request, radioed that he was in the vicinity, and that he would dispatch to the scene. At approximately 9:15 AM he arrived at the scene in a company van with yellow caution lights flashing on top of the panel truck. He parked, per company policy, at the bottom of the hill approximately 75 - 100 yards behind the police cruiser. The ERT, who had $100 \%$ hearing loss in his right ear, then exited the van from the driver's side and walked toward the police cruiser to consult with the police officer on how to best manage traffic at the scene. He was wearing a reflective vest and company uniform. A single-unit truck approached from behind in the right hand travel lane traveling at approximately 55mph and tried to switch lanes when he observed the yellow emergency lights on the panel truck. When the driver of the single-unit truck switched to the middle lane, the driver struck the right-rear end of a semi trailer in the middle lane, and lost control. The driver swerved back into the right lane and tried to brake, sideswiped the ERT's panel truck, then struck the ERT. After being struck, the ERT was thrown over the side of the bridge $75-80$ feet to the ground below. The police officer at the scene immediately radioed dispatch services to summon emergency medical services to the scene. Emergency medical services personnel arrived within minutes, found the ERT under the bridge and observed no vital signs. The police officer contacted the local coroner who arrived and declared the ERT dead at the scene due to "multiple blunt force injuries secondary to motor vehicle versus pedestrian”.

The police report stated that the brakes were found to be defective in the single-unit truck.

\section{Recommendations and Discussions:}

\section{Recommendation No. 1: A traffic control plan should be implemented and enforced immediately when the travel lane is obstructed.}

Discussion: Guidelines set forth by the U.S. Department of Transportation, Federal Highway Administration, Manual on Uniform Traffic Control Devices (MUTCD), Chapter 6D: Pedestrian and Worker Safety; Section 6D.03 Worker Safety Considerations, should be followed by incident responders. In this situation, as stated in the MUTCD Section 6D.03(D), a safety zone for responders should have been created using temporary traffic control techniques such as speed reduction and diverting traffic from the right-hand lane. The MUTCD Chapter 6C.04, Advance Warning Area, describes a method of reducing the speed of traffic on highways by effective placement of the first warning sign in meters (feet) should be substantially longer-from 1.5 to 2.25 times the speed limit in $\mathrm{km} / \mathrm{h}$ (8 to 12 times the speed limit in $\mathrm{mph}$ ). Since two or more advance warning signs are normally used for these conditions, the advance warning area should extend $450 \mathrm{~m}$ (1,500 ft) or more for open highway conditions (see Table 6C-1). Section 6C.08 Tapers, states that tapers are created by using a series of channelizing devices and/or pavement markings to move traffic out of or into the normal path.

49 CFR 392, Subpart C - Stopped Vehicles, 392.22(b)(2(iv) states that "if a commercial motor vehicle is stopped within 500 feet of a curve, crest of a hill, or other obstruction to view, the driver shall place the warning signal required by paragraph (b)(1) of this section in the direction of the obstruction to view a distance of 100 feet to 500 feet from the stopped commercial motor vehicle so as to afford ample warning to other users of the highway” and to place warning 
signals toward traffic and give motorists time to decelerate and adjust to the changing driving conditions.

Ample time and distance should be provided for motorists to adjust to reduced travel speed and lane funneling. This would have created a safer space for the ERT, police, and towing company to maneuver while responding to the situation. Additionally, radio and/or mobile phone communication between the ERT and police should be established prior to arrival on the scene that includes a hazard assessment of the incident and a clear description of duties to be performed by the ERT.

Recommendation No. 2: Ensure that the placement of various types of warning devices (portable signs, orange traffic cones, flares and/or portable changeable message signs) informs drivers of what to expect when approaching an incident scene.

Discussion: Part 6 of the November 2003 edition of the Manual on Uniform Traffic Control Devices (MUTCD) includes Chapter 6I-Control of traffic through traffic incident management areas. Chapter 6I defines a traffic incident management area as "an area of highway where temporary traffic controls are imposed by authorized officials in response to a road user incident, natural disaster, or special event. It extends from the first warning sign or emergency warning lights on a vehicle to the last temporary traffic control device or to a point where vehicles return to the original lane alignment and are clear of the traffic incident.”

Warning devices are a means by which response personnel can convey information to motorists approaching an incident scene, referred to as the "advance warning area." The advance warning area may vary from a single sign or high-intensity rotating, flashing, oscillating, or strobe lights on a vehicle to a series of signs in advance of the incident scene.

Weather conditions, curves and hills that limit visibility of the incident scene require that the advance warning devices be placed at an even greater distance. An incident occurring in an intersection requires advance warning signs, devices, and markings to be used on all cross streets, as appropriate.

Portable signs can be transported on a response vehicle to the incident scene where they can be placed in a location that allows maximum visibility to oncoming traffic. The manual on uniform traffic control devices (MUTCD) states “where special emphasis is needed, signs may be placed on both the left and right sides of the roadway. Signs mounted on portable supports may be placed within the roadway itself. Signs may also be mounted on or above barricades.”

Flares and orange traffic cones may be used individually or together to provide advance warning. To enhance the visibility of the orange traffic cones, flares may be placed next to them, where the glow from the burning flare would reflect off of and illuminate the cone.

At this incident, no flares and or traffic cones were used or other traffic control devices such as signs were used.

Recommendation No. 3: In addition to flashing lights, a permanent message board should be placed on the back of emergency response vehicles that routinely need to control traffic.

Discussion: Permanent message boards on the back of emergency response vehicles provide a safe and effective way to alert and warn motorists of traffic incidents and changes. Portable 
changeable message signs can be used as temporary traffic control devices. The flexibility to display various messages allows the signs to be used in a wide variety of applications (e.g., at a crash or for emergency incident management). The primary purpose of portable changeable message signs is to advise the road user of unexpected situations. Some typical applications may include: where the speed of vehicular traffic is expected to drop substantially; where crash or incident management is needed; or where changes in road user pattern occur.

\section{Recommendation No. 4: Ensure that personnel receive training in the proper procedures and the hazards associated with emergency operations for highway incidents.}

Discussion: Workers who respond to highway incidents have numerous responsibilities, ranging from traffic control to assisting injured or stranded motorists. Responders must be trained to safely conduct multiple tasks near moving traffic. Because of the variability of each incident, all emergency responders should have ongoing, appropriate, task-specific training.

\section{Recommendation No. 5: When providing emergency roadside assistance, company policy for exiting emergency vehicles away from the traffic lanes should be enforced.}

Discussion: According to a company representative, ERTs, when working on busy roadways, were trained to exit vehicles away from traffic and to walk as far away from traffic as possible. In this instance, the ERT had exited from the vehicle on the driver's side and was walking to the police cruiser for consultation regarding the situation. The driver should then have approached the hazardous scene by walking along the outside of the shoulder. This would have created a longer safe zone for responders to work in.

\section{Recommendation No. 6: Braking mechanism performance checks should be routinely performed on all motor vehicles before entering roadways.}

Discussion: The single-unit truck involved in this incident was determined to have defective brakes. A braking mechanism performance check and maintenance of the vehicle should have been performed on the vehicle before entering the roadway to ensure that if emergency braking was needed, the action could be carried out (Federal Motor Carrier Safety AdministrationSubpart C — \$393.40 Required brake systems, §396.3 Inspection, repair and maintenance).

\section{Cause of Death}

The death certificate states the cause of death was due to, "multiple blunt force injuries secondary to motor vehicle versus pedestrian”.

\section{Keywords}

Emergency road service technician

Responder

Semi

Semi-tractor trailer 


\section{References}

1. "Manual for Uniform Traffic Control Devices"

http://mutcd.fhwa.dot.gov/

2. “A Checklist for Highway Crash Site Management”

3. Federal Motor Carrier Safety Administration, 49 CFR 392 Driving of Motor Vehicles, Subpart C - Stopped Vehicles, 392.22 Emergency signals; stopped commercial motor vehicles http://www.fmcsa.dot.gov/rulesregulations/administration $/ \mathrm{fmcsr} /$ fmcsrruletext.asp?rule_toc $=761 \&$ section $=392.22 \&$ section_toc $=$ 1824

4. http://www.ktc.uky.edu/CheckList.pdf

5. “Fire Chief”, Roadside Assistance, March 1, 2001

http://firechief.com/mag/firefighting_roadside_assistance/

6. U.S. Department of Transportation, Federal Highway Administration [2003]. Part 6 Temporary traffic control of the manual on uniform traffic control devices (MUTCD) 2003 edition. Fredericksburg, VA: American Traffic Safety Services Association.

\section{Acknowledgements}

Towing Companies

Employer

Local police

The Kentucky Fatality Assessment \& Control Evaluation Program (FACE) is funded by a grant from the Centers for Disease Control and the National Institute of Safety and Health. The purpose of FACE is to aid in the research and prevention of occupational fatalities by evaluating events leading to, during, and after a work related fatality. Recommendations are made to help employers and employees to have a safer work environment. For more information about FACE and KIPRC, please visit our website at: www.kiprc.uky.edu 


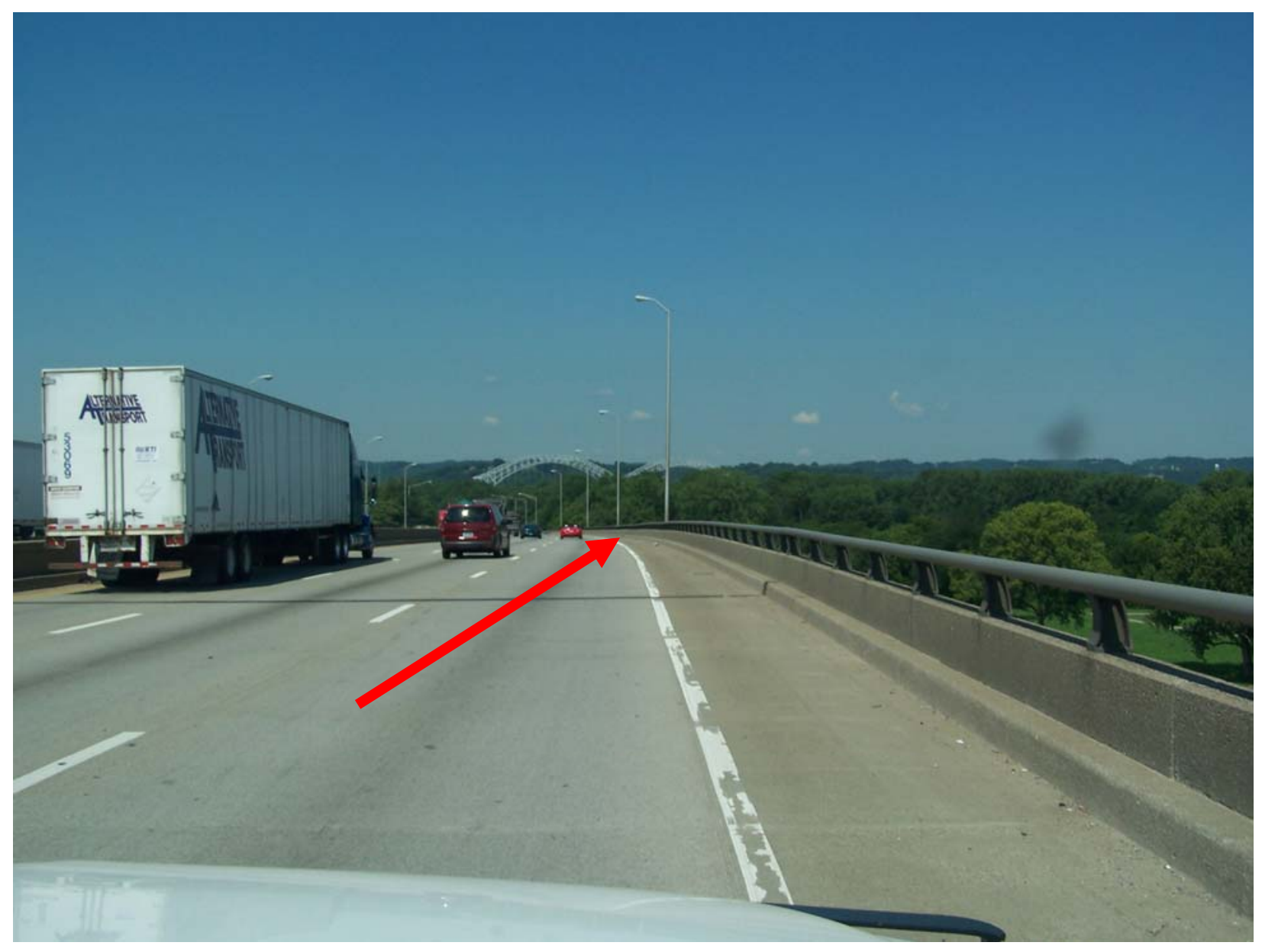

Location where semi parked on shoulder. 